\title{
The Nature of the World Health Organization
}

\author{
By HENRY VAN ZILE HYDE, M.D.
}

$\mathrm{O}$ N AUGUST 18, 1796, Harman Blennerhassett, writing from New Utrecht, Long Island, New York, to a friend in England, told the following tale:

"Some time last summer, a Yankee, at a little town in the State of Massachusetts, learning the times were mortally sickly at Port au Prince, conceived a scheme of sending there a cargo ofcoffins. Those commodities were made up in nests of sizes, from the largest to those for infants and, that no room should be lost, the inner coffins of the nest were packed with cakes ofgingerbread. I have only to add, that the speculation turned out a capital hit-our Yankee having actually returned full freighted with the best West Indies produce, in return for his timber."

On March 17, 1953, 157 years later, a dispatch originating in Port au Prince appeared in the New York Times under the headline: "U. N. and U. S. Help Haiti Fight Yaws-Antibiotic Injections Rapidly Wiping Out Disease Once Infecting 1,000,000."

This dispatch tells the dramatic story of an international cooperative effort to eradicate a disease which is holding back the growth and development of a neighboring nation. It tells of cooperation which involves a number of agen-

Dr. Hyde, now chief of the Public Health Service's Division of International Health, formerly was head of the health staffs of the Technical Cooperation Administration and the Institute of Inter-American Affairs. He has served since 1948 as the United States member of the WHO executive board. cies and governments-cooperation carried on under the inspired and inspiring leadership of the World Health Organization.

Between Blennerhassett's letter of 1796 and the New York Times story of 1953 lies not only the discovery of the causes of infectious disease and their methods of control but also an awakening to the fact that prosperity for all lies in health rather than in disease: in life, rather than in death.

Today, the world reaches out with a helping hand, not with coffins but with trained personnel and with scientific, practical knowledge and skills for the promotion of human health. This is the great purpose of the World Health Organization.

\section{Organization of WHO}

The organizational structure of the WHO follows, in general, the simple pattern characteristic of the other specialized agencies.

A World Health Assembly composed of representatives of all the member states meets annually as the governing body of the World Health Organization. It determines the policies, votes the budget, and assesses the members.

An executive board composed of 18 technically qualified persons designated by 18 governments chosen by the Assembly meets twice annually to review the Director-General's budget proposals and to delve into the many matters of policy, administration, and relationships referred to it by the Assembly.

A secretariat, appointed and lead by the Director-General, carries on the day-to-day work of the Organization.

A feature unique in the United Nations structure is the regional organization of WHO. 
"Learning and knowledge are to be gained from our mistakes as well as from our victories. It is to be hoped that from the work that is being done throughout the world in international health it may be possible for some of the less developed countries to avoid some of the mistakes of the more developed countries. Some short cuts may be made, and a great deal of grief can be avoided by learning from mistakes.

"It is important that we all recognize that no group, no culture, no people, has yet found the perfect way of living-not even of providing medical care. There is something to learn from all patterns and there is something to be discarded from all patterns about which we know anything at the present time. There is much to be learned from the attitudes of the so-called underdeveloped countries. Many of them have developed wisdoms that we have hardly ever had or have forgotten. I think no person has worked in international health-and particularly those who have worked in close contact with the people of the underdeveloped countrieswho has not gained greatly in terms of his own experience and stature and value of his own community. ...

"The people of the underdeveloped countries are very tolerant people, generally. They are willing to absorb the peculiarities of those who come to help them, and some of our customs are very peculiar indeed, from their points of view. It is so easy for us to take for granted that our ways are or should be standard and that if everyone would just do things the way we do them everybody would live happily ever after; there would be no conflicts and everything would be fine. Of course, this is not true. In our own groups and in our own cultures, we also have troubles. We have not yet found all the answers and it would be a very bold person indeed who would go into any underdeveloped country and say: 'You should do as we do and then you will have no more troubles.' Yet occasionally this is the attitude that is taken towards some of the underdeveloped countries. When that does happen the people of those countries are very polite. In effect they say, 'Oh yeah,' and let it go at that. They are far more polite, generally, than we are. They are far more willing to accept our peculiarities than we to accept theirs, and they even try to understand our limitations and make allowances for us."

-Brock Chisholm, M. D.

Director-General, WHO, 1948-53
The World Health Assembly has divided the world into six regions in order to decentralize operations and, to a degree, policy development. In each of these regions there is a regional office and a regional committee. The regional office is headed by a director, appointed by the executive board on the nomination of the regional committee. The regional director reports to the Director-General. The regional committee is composed of the governments of the region. It meets annually to review regional problems and needs and proposed plans and budgets. Program development and budget construction begin at the regional level and finally take form in the Assembly.

Through its decentralization, WHO is brought nearer to the people and to the governments it serves, being more responsive to their needs.

\section{Functions}

The World Health Organization exists in order to render service, first, to the world at large and, second, to its individual membersthe governments of which it is composed.

\section{Services to the World}

There are certain services that must be performed on a world basis if they are to have significance. These services are not new with the World Health Organization. They have grown up during the past half century as the world has become an increasingly more intimate place. They had their origins in the International Office of Public Health, which was founded in 1907, in the Pan American Sanitary Bureau, and in the League of Nations. 
Daily from Singapore, throughout the vast reaches of the Pacific, and from Geneva, and over a network reaching Africa, Europe, and the Americas-WHO broadcasts reports on pestilential disease as a guide to shipping and an aid to quarantine officials. In the East, where cholera, plague and smallpox remain a daily concern, this is a service of first importance. We can hope to see an end of this business in our time. But it is not yet. Unnecessary diseases, including the easily preventable scourges of the Dark Ages, are still the daily companions of vast numbers of our fellow men. That fact must weigh heavily on our own consciences, so long as it remains a fact. Meanwhile, WHO must perform those services which limit such diseases and keep them within bounds.

Certain agents important in medicine and public health are used universally. These include antitoxins, serums, vaccines, antibiotics, vitamins, and insecticides. World War I showed the need for the development of international standards in regard to such products. While tetanus antitoxin manufactured in the United States and that manufactured in France were equally effective, they were differently measured and marked because there was no internationally agreed unit of measurement. As a result, soldiers died horribly and unnecessarily, because of errors in dosage. Today within WHO the world has a system of standardization, serving all people everywhere. In the research laboratory in Bethesda, Md., at the bedside in Rangoon, in the jungle field station on the Congo-scientists, medical officers, and native vaccinators speak the same language. In utilizing WHO standards, they understand one another, immediately and distinctly.

WHO serves as the world clearinghouse in the many fields of knowledge which, taken together, constitute "public health." Through panels of experts drawn from the world at large, it keeps itself abreast of knowledge. On occasion, committees of experts, drawn from these panels are brought together to resolve special problems or advise on current issues. Reports of these committees are basic documents in health throughout the world. There are some 50 such reports now dealing with the control of particular diseases such as tuberculosis, schistosomiasis, and malaria; with training and administration; with broad problems such as environmental sanitation and nursing. The world looks to WHO to keep it reliably informed and up to date.

\section{Services to Members}

A new thing in our generation-an area of great hope and promise-is the service that WHO is rendering to its members in the management of their own health problems and in the development of their own health services. It is here that we can see a new future for the billions of mankind. We see, in the distance, man living as man should-clean, healthy, and productive; free and at peace.

There are three elements to this aspect of the WHO work-advice, demonstration, and training.

1. Advice. The WHO is prepared to send advisers on any phase of public health to governments seeking such assistance. Such advisory service may relate to the organization and administration of public health on a national basis. An international team sent to Israel, for instance, reviewed the national health service at the request of the Government and made important, far-reaching recommendations. Advisory services may also be highly specialized, as when advisers are sent to Chile in connection with the production of diphtheria and whooping-cough vaccine to be used in a nationwide campaign. Advisers are drawn from the permanent central or regional secretariats or, perhaps more often, on a short-term basis from national and local health services, public and private laboratories, universities and foundations in all parts of the world.

2. Demonstration. Carrying advice into the field of practical action, WHO, on the request of governments, conducts demonstrations of modern public health methods. Four WHO demonstrations of malaria control, conducted in widely separated parts of India, created the understanding and popular demand that has led to a nationwide project now being launched with a view to the mass control of malaria in India during the next 3 to 5 years.

In India today there are an estimated 100 million cases of malaria each year. Its control would release some 3 billion man-days of pro- 
ductive effort and lift an incalculable burden of human suffering. Last spring I visited the Terai, the great plains at the base of the Himalayas. I was shown a modern 16,000-acre farm which 2 years previously had been a tiger forest. Only through malaria control had it been possible to open up this fertile area which had been unproductive through the centuries. This was an example of what can be done and is being done in many areas of the world. A WHO demonstration team was at work in the Terai and can be credited with giving new life to an area of great potential.

It has been my privilege to visit many countries in which WHO is at work. I have seen its malaria demonstration teams in the foothills of the Himalayas; its tuberculosis teams in Delhi, Karachi, Baghdad, and El Salvador; its maternal and child health teams in Columbia, Egypt, and Najafghar, India. Even a cursory glance through the Director-General's annual report gives a sense of great accomplishment over wide areas of the world. Vital and vigorous projects are under way. It is, indeed, heartening to find the influence of the World Health Organization reaching so deeply into the far parts of the earth. Demonstration teams are planting seeds of knowledge that are growing among the peoples of the world, that are seen and understood in their deep significance by the governments.

3. Training. While demonstrating ways and means of attaining progress in health, WHO is assisting in building up a corps of trained men and women, everywhere, to do the job that must be done. During its short career, WHO has awarded 2,608 fellowships for foreign study to physicians, nurses, sanitary engineers, and other technicians. This group, with the thousands trained under the auspices of private foundations and various government programs, are the world health leaders of the future.

To a large extent, WHO owes its own existence to the leadership of men and women who, a generation ago, had similar opportunities for foreign study under the Rockefeller Foundation program.

The WHO training program is not limited to fellowships alone. Teaching missions, regional seminars, visiting lecturers, and other
"I am told and I have observed personally in many countries, that mothers and fathers in the less developed countries love their children dearly. These people dislike illness and suffer pain as much as we do. In the Near and Far East you will see many blind and near blind people on the streets; people with sore eyes, living skeletons engaged in hard work, many, many hopeless cripples. So the survivors of the perils of infancy look forward to lives of sickness and pain, brought to a premature close long before they have lived out the normal span of life. ... We must face the question as to whether in similar circumstances, we would not be apt to embrace any doctrine no matter how evil, if it gave us hope of relief from sickness, pain, and premature death. One thing we can do, and the quicker we do it the better, is to help the people of the less fortunate countries to clear away the mass diseases, for there can be no economic development, no rise in the standard of living, until this barrier has been removed. We must then go on to help them to develop their material and human resources, and in both of these things the World Health Organization is best fitted of all UN agencies to lead the way."

-Frank G. Boudreau, M.D.

available devices are utilized to build the strength of teaching institutions around the world.

\section{Coordination}

The World Health Organization is not working alone. Rather, it is the coordinating force in a complicated structure of many agencies. Under its constitution it is the "coordinating and directing authority in international health work."

There are a number of agencies concerned with various aspects of world health: United Nations International Children's Emergency Fund; United Nations Educational, Scientific, and Cultural Organization (UNESCO); the Food and Agricultural Organization (FAO); the Technical Cooperation Administration (TCA); the Mutual Security Administration (MSA); the Colombo Plan; private agencies 
and foundations, industry, churches, and others. Each has its special motivation, its special drives, its own resources, its special values.

It is not strange that the world should be a complicated environment. Certainly a local community is a complicated affair with its several departments of local government, its P'TA's, Rotary Club, women's clubs, church groups, chamber of commerce ad infinitum. A concept that the world should be simpler than the town is not a valid one. The job of the World Health Organization is not, as some have proposed, to stand alone and do the whole job of international health. Rather, its job is to mobilize the great forces that are available; to give the lead to us all.

It is doing this. It is increasingly setting the sights for all agencies, pointing up opportunities for social and economic advancement through health improvement. It has brought about jointness of operation in the place of what could have been duplication and waste. Examples of its coordinating activity are found in joint committees with FAO, ILO (International Labor Organization), and UNICEF, and in the holding of coordinating conferences among the operating staffs of the various agencies in the field of health. Such conferences have been held at the country level. They are held regularly in certain regions and have been held at the world level in Geneva.

In February 1953, for instance, a joint staff conference of the TCA health staff in Africa and Asia and the WHO headquarters and regional staffs was held in Geneva. It has led to a depth of understanding and intimacy of relationship which could be attained in no other way.

In health it is fair to say that under the leadership of the World Health Organization the various national and international programs have become, in a very real sense, a single, unified movement with a common goal and common methods of attaining that goal.

During 1952, 12,600 villages, one-third of all the villages in Iran, in which are the homes of some 4 million Iranians, were treated with DDT. The report of the United States Director of Technical Cooperation-the Point IV
"Nations must work together for their common good against their common enemies-violence, poverty, ignorance and disease. We can't take them on one at a time because they are all tied together, and we can't act alone because we're all tied together. The late Justice Holmes said that continuity with the past is not a duty. It is only a necessity. I would say the same of international cooperation. It is not a duty. It is only a necessity."

- Ambassador James J. Wadsworth,

Deputy United States Representative to the United Nations

program-which contributed substantial sums to this campaign, includes the following statement:

"This campaign against malaria in Iran is a truly international effort. Iran's Ministry of Health, Institute of Malariology of the University of Tehran School of Medical Sciences, the World Health Organization's Malaria Control Advisory Team consisting of a malariologist, an entomologist and a sanitary engineer, and Point IV have all joined in this program in Iran. Cooperation and coordination has been excellent considering the great area of Iran, poor communications and usually bad roads, and other organizational problems of an undertaking as great as this program. The WHO team are 'tops' and to them must go much of the credit for the technological success."

Indeed, international cooperation is a living reality. In the World Health Organization, there is represented something new and fine which has come into the world since the Yankee trader took his profits from "mortally sickly" Haiti. We, as United States citizens, can take a great measure of satisfaction in this change to which we, as a nation and a people, have contributed so much of goods and spirit. We can take pride in America's part in building WHO. We can explain this to our fellow citizens so that they too may find satisfaction in a job well done and worth pushing ever forward. 